\title{
Traditional knowledge and climate change: a new legal frontier?
}

\author{
Annalisa Savaresi ${ }^{*}$ \\ Lecturer in Environmental Law, University of Stirling, UK
}

The Paris Agreement is the first climate treaty to include a reference to traditional knowledge, opening up a new legal frontier to address this complex subject in international law. Traditional knowledge has already been the subject of considerable regulatory developments in international environmental and human rights instruments. This article reflects on how these bodies of law treat traditional knowledge, with the objective of understanding what are the gaps that could and should be addressed in the context of the climate regime. The article is divided into four parts. The introduction outlines the article's structure and methodology. Section 2 provides a definition of traditional knowledge and identifies the international law questions it raises. Section 3 analyses existing international obligations on traditional knowledge in environmental and human rights law. Section 4 considers the interplay between the climate regime and the bodies of international law analysed in Section 3. The conclusion offers some recommendations on the treatment of traditional knowledge in the climate regime.

Keywords: traditional knowledge, climate change law, Paris Agreement, international environmental law, human rights

Note: Before the publication of this article, at COP23 in Bonn in November 2017, the Parties to the climate regime adopted a decision on the operationalization of the Local Communities and Indigenous Peoples Platform. ${ }^{1}$

The decision specifies that the overall purpose of the platform is to "strengthen the knowledge, technologies, practices and efforts of local communities and indigenous peoples related to addressing and responding to climate change, to facilitate the exchange of experience and the sharing of best practices and lessons learned on mitigation and adaptation in a holistic and integrated manner and to enhance the engagement of local communities and indigenous peoples in the UNFCCC process'. ${ }^{2}$ Work towards the full operationalization of the platform is expected to continue in 2018.

* Email: annalisa.savaresi@ stir.ac.uk. The author acknowledges support received from the project 'BENELEX: Benefit-sharing for an Equitable Transition to the Green Economy - the Role of Law'<https://www.strath.ac.uk/research/strathclydecentreenvironmentallawgovernance/benelex/> funded by the European Research Council Starting Grant, for the preparation of this paper. The author is grateful to the editors, Dr Claire Charters, Prof Elisa Morgera, Dr Louisa Parks, Elsa Tsioumani and Dr Saskia Vermeylen for comments on earlier drafts of this paper. The usual disclaimers apply.

1. Provisionally numbered FCCC/SBSTA/2017/L.29.

2. Para 5 . 


\section{INTRODUCTION}

A host of international law instruments on matters as diverse as human rights, ${ }^{3}$ biodiversity, ${ }^{4}$ cultural heritage, ${ }^{5}$ desertification, ${ }^{6}$ and food and agriculture ${ }^{7}$ acknowledge the important role of traditional knowledge for cultural identity, human well-being and the understanding and preservation of ecosystems. Conversely, even though scientists have increasingly recognized its importance as a means to assess, mitigate and adapt to climate change, ${ }^{8}$ the United Nations Framework Convention on Climate Change ${ }^{9}$ (UNFCCC) is the only 'Rio Convention' ${ }^{10}$ not to mention traditional knowledge. This state of affairs has recently changed with the adoption of the Paris Agreement. ${ }^{11}$ Building upon earlier practice of the climate regime's treaty bodies, ${ }^{12}$ the Agreement acknowledges that adaptation should be based on and guided by, amongst other things, 'traditional knowledge, knowledge of indigenous peoples and local knowledge systems' ${ }^{13}$ As a result, parties to the climate regime have recently begun work on an indigenous peoples and local communities' platform for the exchange of experiences and sharing of best practices on mitigation and adaptation. ${ }^{14}$

The reference to traditional knowledge included in the Paris Agreement and the work on the new platform raise fundamental questions concerning the specific regulatory needs arising in relation to traditional knowledge under the climate regime, and their intersection with existing international law obligations on traditional knowledge.

3. United Nations Declaration on the Rights of Indigenous Peoples (13 September 2007) A/RES/61/295 ['UNDRIP'], article 31.

4. Convention on Biological Diversity (Rio de Janeiro, 5 June 1992, in force 29 December 1993) 1760 UNTS 79 ['CBD'] articles 8(j) and 10(c).

5. UNESCO Convention on the Protection and Promotion of the Diversity of Cultural Expressions (Paris, 18 March 2007, in force 20 October 2010) 2440 UNTS 311, Preamble.

6. UN Convention to Combat Desertification in Countries Experiencing Serious Drought and/or Desertification, Particularly in Africa (Paris, 14 October 1994, in force 26 December 1996) 1954 UNTS 3 ['UNCCD'], article 18.2(b).

7. International Treaty on Plant Genetic Resources for Food and Agriculture (Rome, 3 November 2001, in force 29 June 2004) 2400 UNTS 303 ['ITPGR'], article 9.2(a).

8. Intergovernmental Panel on Climate Change ['IPCC'], Climate Change 2014: Impacts, Adaptation, and Vulnerability. Part A: Global and Sectoral Aspects. Contribution of Working Group II to the Fifth Assessment Report of the Intergovernmental Panel on Climate Change (Cambridge University Press, Cambridge 2014), 758, 765 and 766.

9. United Nations Framework Convention on Climate Change (New York, 9 May 1992; in force 21 March 1994) 1771 UNTS 107 ['UNFCCC'].

10. This term is commonly used to refer to the CBD, UNCCD and UNFCCC.

11. Paris Agreement (Paris, 12 December 2015, in force 4 November 2016) UNTS yet to be attributed.

12. Decision 1/CP.16, The Cancún Agreements: Outcome of the Work of the Ad Hoc Working Group on Long-term Cooperative Action under the Convention (2010) FCCC/CP/2010/7/ Add.1, 12; Decision 2/CP.17, Outcome of the work of the Ad Hoc Working Group on Longterm Cooperative Action under the Convention FCCC/CP/2011/9/Add.1 (2011), 93(b); Decision 18/CP.19, National Adaptation Plans, FCCC/CP/2013/10/Add.2/Rev.1 (2013), 7; and Decision 4/CP.20, Report of the Adaptation Committee, FCCC/CP/2014/10/Add.2 (2013), 4. 13. Paris Agreement, article 7.5. For the sake of expediency, I use the term 'traditional knowledge' to refer to all these terms, unless otherwise specified.

14. Decision 1/CP.21, Adoption of the Paris Agreement, FCCC/CP/2015/10/Add.1 (2015), paras 135-6; and Report of the Conference of the Parties on its twenty-second session, held in Marrakech from 7 to 18 November 2016, Part I, FCCC/CP/2016/10 (2016), 163-7. 
This article looks at these matters, identifying lessons learned from other international instruments dealing with traditional knowledge; areas where these may provide guidance to parties to the climate regime; and remaining gaps in the law. The analysis shows that the treatment of traditional knowledge is laden with complexities ${ }^{15}$ associated with the specificities of different types of traditional knowledge and of different knowledge-holders. Because of these complexities, international law to date has largely focused on supporting the protection and promotion of the use of traditional knowledge at the national, subnational and local levels, striving to eliminate perverse incentives to breach the rights of knowledge-holders. International law has however addressed these matters in a largely fragmentary fashion, and little systemic understanding of state obligations in this connection seems to exist.

Scholarly literature has made limited efforts to understand the interplay between international law instruments and processes dealing with traditional knowledge, ${ }^{16}$ and largely - though not exclusively ${ }^{17}$ - focuses on biodiversity ${ }^{18}$ and intellectual property law. ${ }^{19}$ Building on this literature, this article sets out to analyse international

15. See eg RJ Coombe, 'The Recognition of Indigenous Peoples' and Community Traditional Knowledge in International Law' (2001) 14 St Thomas Law Review 275; Brendan Tobin, 'Redefining Perspectives in the Search for Protection of Traditional Knowledge' (2001) 10 Review of European Comparative \& International Environmental Law 47; P Hardison, 'Report on Traditional Knowledge Registers (TKRs) and Related Traditional Knowledge Databases (TKDBs)' (CBD Secretariat 2005); A Taubman, 'Saving the Village: Conserving Jurisprudential Diversity in the International Protection of Traditional Knowledge', in KE Maskus and JH Reichmann (eds), International Public Goods and Transfer of Technology Under a Globalized Intellectual Property Regime (Cambridge University Press, Cambridge 2005).

16. With the salient exception of Lucas Lixinski, Intangible Cultural Heritage in International Law (Oxford University Press, Oxford 2013), who nevertheless focuses on intangible cultural heritage.

17. See eg Coombe (n 15); A Meyer, 'International Environmental Law and Human Rights: Towards the Explicit Recognition of Traditional Knowledge' (2001) 10 Review of European Community and International Environmental Law 37; Z Aksoy, 'Global Governance of Traditional Knowledge and its Justice Implications: A Case for an Alternative Approach' <https:// www.iss.nl/sites/corporate/files/3-ICAS_CP_Aksoy.pdf> accessed 26 July 2017; JW Brewer and EA Kronk, 'Guarding Against Exploitation: Protecting Indigenous Knowledge in the Age of Climate Change' (2015) <http://papers.ssrn.com/abstract=2567995> accessed 27 July 2017; T Williams and P Hardison, 'Culture, Law, Risk and Governance: Contexts of Traditional Knowledge in Climate Change Adaptation' [2013] Climatic Change 531; M Burkett, 'Indigenous Environmental Knowledge and Climate Change Adaptation', in RS Abate and EA Kronk (eds), Climate Change and Indigenous Peoples: The Search for Legal Remedies (Edward Elgar Publishing, Cheltenham, UK and Northampton, MA, USA 2013).

18. See eg EC Kamau and G Winter (eds), Genetic Resources, Traditional Knowledge and the Law: Solutions for Access and Benefit Sharing (Earthscan, London 2009); G Singh Nijar, 'Incorporating Traditional Knowledge in an International Regime on Access to Genetic Resources and Benefit Sharing: Problems and Prospects' (2010) 21 European Journal of International Law 457; K Bavikatte and DF Robinson, 'Towards a People's History of the Law: Biocultural Jurisprudence and the Nagoya Protocol on Access and Benefit Sharing' (2011) 7 Law, Environment \& Development 35; G Singh Nijar, 'Traditional Knowledge Systems, International Law and National Challenges: Marginalization or Emancipation?' (2013) 24 European Journal of International Law 1205.

19. See eg K Aoki, 'Neocolonialism, Anticommons Property, and Biopiracy in the (Not-soBrave) New World Order of International Intellectual Property Protection' (1998) 6 Indiana Journal of Global Legal Studies 11; M Halewood, 'Indigenous and Local Knowledge in International Law: A Preface to Sui Generis Intellectual Property Protection' (1999) 44 McGill Law 
law on traditional knowledge as it is (de lege lata) with the objective of understanding how this complex subject matter should be addressed in future (de lege ferenda) in the context of the climate regime.

The present article places particular emphasis on international human rights obligations associated with traditional knowledge. The Human Rights Council has noted how 'human rights obligations, standards and principles have the potential to inform and strengthen international, regional and national policymaking in the area of climate change, promoting policy coherence, legitimacy and sustainable outcomes'. ${ }^{20}$ The Paris Agreement's reference to human rights and to the rights of indigenous peoples and local communities ${ }^{21}$ may be regarded as an opening to greater cross-fertilization and institutional cooperation between these two regimes. This opening has already engendered a flurry of developments. The Human Rights Council special procedures $^{22}$ and the Office of the High Commissioner on Human Rights have undertaken to make formal submissions in the context of negotiations on the rulebook of the Paris Agreement on matters such as gender, adaptation and the Sustainable Development Mechanism, ${ }^{23}$ elaborating recommendations on how to integrate human rights into

Journal 953; DR Downes, 'How Intellectual Property Could Be a Tool to Protect Traditional Knowledge' (2000) 25 Columbia Journal of Environmental Law 253; G Dutfield, Intellectual Property Rights, Trade and Biodiversity: Seeds and Plant Varieties (3rd edn, World Conservation Union, London 2000); T Cottier and M Panizzon, 'Legal Perspectives on Traditional Knowledge: The Case for Intellectual Property Protection' (2004) 7 Journal of International Economic Law 371; RJ Coombe, 'Protecting Traditional Environmental Knowledge and New Social Movements in the Americas: Intellectual Property, Human Right, or Claims to an Alternative Form of Sustainable Development' (2005) 17 Florida Journal of International Law 115; DJ Gervais, 'Traditional Knowledge \& Intellectual Property: A TRIPS-Compatible Approach' [2005] Michigan State Law Review 137; L Whitt, Science, Colonialism and Indigenous Peoples (Cambridge University Press, Cambridge 2009); LR Helfer and GW Austin, Human Rights and Intellectual Property: Mapping the Global Interface (Cambridge University Press, Cambridge 2011); P Drahos and S Frankel (eds), Indigenous Peoples' Innovation: Intellectual Property Pathways to Development (The Australian National University E Press, Canberra 2012).

20. Human Rights Council Resolutions 7/23, A/HRC/7/78 (2008); 10/4, A/HRC/RES/10/4 (2009), Preamble; 26/27, A/HRC/RES/26/27 (2014), Preamble; and 35/32, A/HRC/35/L.32 (2017), Preamble.

21. Paris Agreement, Preamble.

22. Acting upon the Council's exhortations, see eg Human Rights Council Resolution 35/32 (n 20), 5.

23. OHCHR response to UNFCCC Secretariat request for submissions on the Nairobi Work Programme: impacts, vulnerability and adaptation to climate change: Health impacts, including occupational health, safety and social protection, FCCC/SBSTA/2016/2, para 15(a)(i), 2016; OHCHR response to the UNFCCC Secretariat request for submissions on the Lima Work Programme on Gender: Views on possible elements and guiding principles for continuing and enhancing the work programme (SBI), FCCC/SBI/2016/L.16, paragraph 5, 2016; OHCHR response to the UNFCCC Secretariat request for submissions on the Paris committee on Capacity-Building: Views on the annual focus area or theme for the Paris Committee on Capacity-Building for 2017 (SBI), FCCC/SBI/2016/L.24, 2016; OHCHR response to UNFCCC Secretariat request for submissions on the Paris Agreement (APA): Views and guidance related to intended nationally determined contributions, adaption communications, the transparency framework, and the global stocktake, and for information, views and proposals on any work of the APA, FCCC/APA/ 2016/2, 2016; and OHCHR response to UNFCCC Secretariat request for submissions on the future UNFCCC Sustainable Development Mechanism: Regarding the rules, modalities and 
climate policy. ${ }^{24}$ The UN Special Rapporteur on Human Rights and the Environment, John Knox, has furthermore noted how human rights bodies can inform and improve the making of international climate change law and policy, highlighting issues "that might otherwise be overlooked'. ${ }^{25}$ This article therefore considers the specific role of human rights law in complementing state obligations in relation to traditional knowledge under the climate regime.

The remainder of the article is structured as follows. Section 2 provides a definition of traditional knowledge and of the regulatory questions investigated in the analysis. Section 3 analyses existing international obligations on traditional knowledge, distinguishing between environmental and human rights law. Section 4 considers the specificities of climate change law when compared with existing international law, as well as developments that may occur in the future. The conclusion offers some recommendations on the future treatment of traditional knowledge in the climate regime.

\section{DEFINING TRADITIONAL KNOWLEDGE}

Although traditional knowledge is mentioned in a plethora of instruments and processes, there is no single definition of it in international law. Instead, international instruments use expressions such as 'traditional knowledge', 'indigenous peoples' knowledge' or 'local knowledge' to refer to knowledge that is often characterized by the subjects who hold it (eg indigenous peoples, local communities, traditional healers, pastoralists, etc.) and by the processes through which it is produced, in contradistinction to so-called 'modern science'. ${ }^{26}$

The Intergovernmental Panel on Biodiversity and Ecosystem Services (IPBES) ${ }^{27}$ has recently attempted to define the notion of traditional knowledge in the context of its mandate to "explore ways and means to bring different knowledge systems, including indigenous knowledge systems, into the science-policy interface' ${ }^{28}$ In this connection, the IPBES has relied ${ }^{29}$ upon Berkes's widely cited definition of traditional knowledge as 'a cumulative body of knowledge, practice and belief, evolving by adaptive processes and handed down through generations by cultural transmission,

procedures for the mechanism established by Article 6, paragraph 4, of the Paris Agreement, para 100, 2016. All OHCHR submissions are available at <http://www.ohchr.org/EN/Issues/HRAndClimateChange/Pages/UNFCCC.aspx> accessed on 26 July 2017.

24. The OHCHR hosted an expert meeting on climate change and human rights on 6-7 October 2016 in Geneva. The Draft Recommendations elaborated at the meeting are available at <http://www.ohchr.org/EN/Issues/HRAndClimateChange/Pages/ClimateChange.aspx $>$ accessed on 26 July 2017.

25. Report of the Special Rapporteur on the issue of human rights obligations relating to the enjoyment of a safe, clean, healthy and sustainable environment, John H Knox, A/HRC/31/52, 1 February 2016, 89.

26. Compare for example the Climate and Traditional Knowledges Workgroup, 'Guidelines for Considering Traditional Knowledges in Climate Change Initiatives' <https://climatetkw. wordpress.com/guidelines/> accessed 27 March 2017, iii.

27. The IPBES was established to strengthen the science-policy interface for biodiversity, carry out knowledge generation catalysis, policy support and capacity building - IPBES, Functions, Operating Principles and Institutional Arrangements of IPBES, 21 April 2012, Panama City, Appendix 1, 1.

28. Ibid, $15(\mathrm{~g})$.

29. IPBES, Consideration of Initial Elements: Recognizing Indigenous and Local Knowledge and Building Synergies with Science, EPIPBES/1/INF/5 (2012), 3. 
about the relationship of living beings (including humans) with one another and with their environment'. ${ }^{30}$ This definition distinguishes between empirical knowledge on matters such as animals, plants, soils and landscape; knowledge of resource management systems; institutions of knowledge that frame the process of social memory, creativity and learning; and lastly, overarching cosmologies that shape traditional knowledge-holders' perception of the environment (Figure 1). ${ }^{31}$

Although Berkes's conceptualization is clearly a simplification, ${ }^{32}$ it is helpful for understanding the way international law on traditional knowledge has developed. Some international instruments, in fact, discretely focus only on some of the levels of knowledge identified by Berkes. For example, the Nagoya Protocol to the Convention on Biological Diversity only concerns knowledge on non-human genetic resources, restricting access to such knowledge by drawing up a regime of contractualization and propertization. ${ }^{33}$ Conversely, the UN Educational, Scientific and Cultural Organization (UNESCO) Convention for the Safeguarding of Intangible Cultural Heritage $^{34}$ encourages states to inventory traditional knowledge with the objective

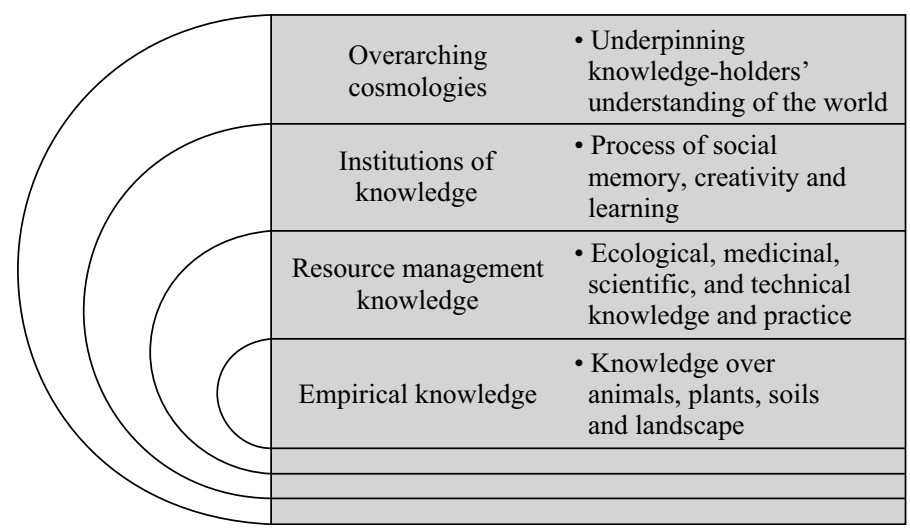

Figure 1 The four levels of traditional knowledge, adapted from Fikret Berkes, Sacred Ecology (Routledge, 2012)

30. See F Berkes, Sacred Ecology (3rd edition, Routledge, Abingdon 2012) 7.

31. Ibid, 18.

32. Ibid. See also F Berkes, J Colding and C Folke, 'Rediscovery of Traditional Ecological Knowledge as Adaptive Management' (2000) 10 Ecological Applications 1251, 1258.

33. Nagoya Protocol on Access to Genetic Resources and the Fair and Equitable Sharing of Benefits Arising from their Utilization to the Convention on Biological Diversity (Nagoya 29 October 2010, in force 12 October 2014) 30619 UNTS 27, especially articles 7 and 12. See eg Aksoy (n 17); C Guneratne, 'Farmers, Indigenous and Local Communities and Traditional Knowledge', in Genetic Resources, Equity and International Law (Edward Elgar Publishing, Cheltenham, UK and Northampton, MA, USA 2012); CB Graber, 'Institutionalization of Creativity in Traditional Societies and in International Trade Law' (Social Science Research Network 2011) SSRN Scholarly Paper ID $1674272<$ http://papers.ssrn.com/abstract=1674272> accessed 27 July 2017; Lixinski (n 16).

34. As observed also eg in Francesco Francioni, 'Cultural Heritage', in Max Planck Encyclopedia of Public International Law (2013). 
of giving it greater visibility. ${ }^{35}$ These instruments invariably pursue the objective of protecting traditional knowledge-holders against appropriation of their knowledge typically by restricting access and use; and/or promoting the diffusion and use of traditional knowledge in order to pursue global public goods, such as biodiversity conservation - typically through documentation and inventorying processes. The tension between these two competing objectives is, however, not easy to reconcile. ${ }^{36}$ This is where human rights law potentially has an important role to play, as, instead, it holistically pursues the protection of traditional knowledge as part of culture without focusing on any one of the levels identified by Berkes. The next section looks at how international environmental law and international human rights law address traditional knowledge, with the aim of clarifying states' obligations and highlighting the challenges that have been encountered under each regime.

\section{EXISTING INTERNATIONAL LAW OBLIGATIONS CONCERNING TRADITIONAL KNOWLEDGE}

The making of international environmental law and policy can be subdivided into four intertwining processes: issue definition, fact-finding, bargaining, and regime strengthening. ${ }^{37}$ While international climate change law relating to traditional knowledge has only very recently entered a formal regulatory phase, a vast web of international law obligations on traditional knowledge already exists. These obligations are not coherently included in a single dedicated treaty but scattered throughout a wide array of instruments that deal with traditional knowledge from a subject-specific perspective. ${ }^{38}$ This section looks at states' obligations on traditional knowledge under international environmental law first, to then consider obligations under human rights law.

\subsection{Traditional knowledge in international environmental law}

Traditional knowledge has been the subject of considerable regulation in international environmental law, which largely focuses on the first two levels of Berkes's conceptualization, that is, empirical knowledge and resource management knowledge. This focus is justified by the mandates of international environmental instruments, none of which aims to protect or promote traditional knowledge ex se. Rather, international environmental law addresses traditional knowledge only in so far as it is relevant to achieving environmental objectives. For example, international biodiversity law is only concerned with the protection and the promotion of the use of traditional

35. Comparative reflections on traditional knowledge documentation may be found in Hardison (n 15); A Merle et al., 'The Role of Registers and Databases in the Protection of Traditional Knowledge: A Comparative Analysis' (UNU-IAS 2004) <http://trove.nla.gov.au/ version/21150498> accessed 27 July 2017.

36. As noted also in Coombe (n 15) 276.

37. As suggested in G Porter, J Welsh Brown and PS Chasek, Global Environmental Politics (Westview Press, Boulder, CO 2000), 79.

38. For a detailed analysis, see A Savaresi, 'Doing the Right Thing with Traditional Knowledge in International Law: Lessons for the Climate Regime' (2016) <http://papers.ssrn.com/ sol3/papers.cfm?abstract_id=2780332 $>$ accessed 26 July 2017. The reflections in this section draw and build upon this work. 
knowledge that is 'relevant for the conservation and sustainable use of biological diversity'. 39

Promotion and protection objectives often coexist in international environmental instruments, which, rather typically, strive to ensure that traditional knowledge-holders - for example traditional healers, pastoralists, indigenous peoples - continue to produce and nurture knowledge, while at the same time enabling this knowledge to contribute to the provision of global public goods, such as fighting biodiversity loss or desertification.

Following a series of infamous cases,${ }^{40}$ international biodiversity law has developed a series of rules on who may access traditional knowledge and under what conditions, requiring that adequate benefits flow to knowledge-holders. This outcome has been achieved in different ways in different treaties. The Nagoya Protocol relies on bilateral contracts between knowledge users and holders to regulate access and use,${ }^{41}$ whereas the International Treaty on Plant Genetic Resources for Food and Agriculture (ITPGR) has pioneered the establishment of a global database and a multilateral benefits scheme. ${ }^{42}$

Conversely, other international environmental instruments envision traditional knowledge as something that ought to flow into the public domain and become widely accessible to enable the pursuit of global public goods, such as combating desertification. ${ }^{43}$ In these instances, international instruments focus on establishing the means of promoting the use of traditional knowledge. The UN Convention to Combat Desertification in Countries Experiencing Serious Drought and/or Desertification, Particularly in Africa (UNCCD), for example, imposes documentation obligations upon its parties, with the aim of diffusing the use of traditional knowledge to avert desertification. ${ }^{44}$ Similar to the UNESCO Convention for the Safeguarding of Intangible Cultural Heritage, this documentation is aimed at the pursuit of a global public good. ${ }^{45}$

International environmental treaties have nevertheless made some progress in creating international obligations concerning the protection of traditional knowledgeholders at the national, subnational and local levels. These obligations typically resort to prior informed consent (PIC) and fair and equitable benefit-sharing requirements to balance the need to preserve traditional knowledge and enable its continued deployment and development, while securing respectful interaction with its holders. There is, nevertheless, a great degree of variation concerning whether and how these requirements are used, and often a remarkable lack of clarity as to the precise scope of states' obligations. For example, while all international environmental law instruments include

39. CBD article 8(j), emphasis added.

40. See eg R Wynberg, 'Rhetoric, Realism and Benefit Sharing: Use of Traditional Knowledge of Hoodia Species in the Development of an Appetite Suppressant' (2004) 7 Journal of World Intellectual Property 851; S Vermeylen, "Contextualizing "Fair" and "Equitable": The San's Reflections on the Hoodia Benefit-Sharing Agreement' (2007) 12 Local Environment 423; R Wynberg, D Schroeder and R Chennells, Indigenous Peoples, Consent and Benefit Sharing: Lessons from the San-Hoodia Case (Springer, Dordrecht et al. 2009).

41. Nagoya Protocol on Access to Genetic Resources and the Fair and Equitable Sharing of Benefits Arising from their Utilization to the Convention on Biological Diversity (Nagoya 29 October 2010, in force 12 October 2014) 30619 UNTS 27, especially articles 7 and 12.

42. ITPGR, article 11.

43. As also argued in the Climate and Traditional Knowledges Workgroup (n 26), 5.

44. UNCCD, article 18(2)a.

45. Traditional knowledge is widely understood to be a component of intangible cultural heritage. See eg. Human Rights Council, Promotion and Protection of the Rights of Indigenous Peoples with Respect to Their Cultural Heritage. Study by the Expert Mechanism on the Rights of Indigenous Peoples, A/HRC/30/53 (2015), Annex, 1. 
benefit-sharing requirements, ${ }^{46}$ some instruments generically identify 'indigenous and local communities' as beneficiaries, ${ }^{47}$ whereas others only focus on farmers in developing countries. ${ }^{48}$ Similarly, international biodiversity law envisions the building of benefit-sharing into contractual arrangements, but falls short of creating obligations to ensure that these arrangements are fair. ${ }^{49}$ Finally, while PIC requirements have been progressively embedded in international biodiversity law, ${ }^{50}$ national lawmakers enjoy a wide margin of appreciation on what they are required to do to satisfy these, ${ }^{51}$ and no PIC requirements appear in the ITPGR ${ }^{52}$ although they may arguably be regarded as implicit in both. ${ }^{53}$

It therefore comes as no surprise that the treatment of traditional knowledge in international environmental law has been the subject of some criticism. International biodiversity law has been criticized for its excessive deference to national law, ${ }^{54}$ and for its timid approach to the protection of the rights of indigenous peoples. ${ }^{55}$ The ITPGR has been criticized for failing to offer an alternative to a predominantly intellectual-property-oriented approach to plant genetic resources for food and agriculture and related traditional knowledge, as well as for failing adequately to secure the protection of farmers' rights. ${ }^{56}$ Shortcomings in the treatment of traditional knowledge in international environmental law are also evident in the practice of the IPBES,

46. See the analysis in Savaresi, 'Doing the Right Thing with Traditional Knowledge in International Law: Lessons for the Climate Regime' (n 38) 29-31.

47. CBD, article 8(j).

48. ITPGR, article 18(4).

49. As observed also in A Savaresi, 'The International Human Rights Law Implications of the Nagoya Protocol', in E Morgera, M Buck and E Tsioumani (eds), The 2010 Nagoya Protocol on Access and Benefit-sharing in Perspective (Martinus Nijhoff, Leiden 2013), 78.

50. Nagoya Protocol, article 7; and Mo'otz kuxtal Voluntary Guidelines for the development of mechanisms, legislation or other appropriate initiatives to ensure the 'prior and informed consent', 'free, prior and informed consent' or 'approval and involvement', depending on national circumstances, of indigenous peoples and local communities for accessing their knowledge, innovations and practices, for fair and equitable sharing of benefits arising from the use of their knowledge, innovations and practices relevant for the conservation and sustainable use of biological diversity, and for reporting and preventing unlawful appropriation of traditional knowledge, CBD/COP/DEC/XIII/18 (2016).

51. As can be evinced from the use of expressions such as 'subject to national legislation' in CBD, article 8(j) and Nagoya Protocol, article 6(2).

52. C Chiarolla, S Louafi and M Schloen, 'An Analysis of the Relationship between the Nagoya Protocol and Instruments Related to Genetic Resources for Food and Agriculture and Farmers' Rights', in E Morgera, M Buck and E Tsioumani (eds), The 2010 Nagoya Protocol on Access and Benefit-sharing in Perspective (Martinus Nijhoff, Leiden 2013) 97.

53. Ibid., 104, and UNESCO Convention, article 13(d)(ii), as interpreted in Operational Directives for the Implementation of the Convention for the Safeguarding of the Intangible Cultural Heritage, 2014, Chapters I and III.

54. Lixinski (n 16), 219.

55. See eg G Dutfield, 'Protecting the Rights of Indigenous Peoples: Can Prior Informed Consent Help?', in R1 Wynberg, D Schroeder and R Chennells (eds), Indigenous Peoples, Consent and Benefit Sharing (Springer, Dordrecht et al. 2009), 55; Grand Council of the Crees (Eeyou Istchee) et al., 'Nagoya Protocol on Access and Benefit Sharing: Substantive and Procedural Injustices relating to Indigenous Peoples' Human Rights' available at: <https://www.cbd.int/ abs/doc/protocol/icnp-1/joint-submission-grand-council-and-others-en.pdf> last visited 27 July 2017).

56. Aksoy (n 17), 13. 
which faces unresolved questions concerning the empowerment of traditional knowledgeholders to contribute to assessment processes, as well as a lack of adequate finance and capacity-building mechanisms. ${ }^{57}$

In sum, under international environmental law, the protection of traditional knowledge is not an end in and of itself, ${ }^{58}$ but is limited to instances when it is relevant for, and compatible with, the achievement of environmental objectives, such as the conservation and sustainable use of biological diversity. International environmental law has not developed a consistent approach to preventing the misuse and misappropriation of traditional knowledge and to eliminating perverse incentives to its use without respect or recognition for the rights of its holders. Each of the various approaches adopted has its limitations. As explained above, documentation and inventorying processes, such as those envisioned in the UNCCD, face the challenge of adequately involving traditional knowledge-holders while respecting their rights, including the choice not to participate in such processes. Contractual approaches restricting access to traditional knowledge, such as that envisioned in the Nagoya Protocol, do not address the inherent power imbalances between traditional knowledge-holders and users. ${ }^{59}$ Finally, international environmental law does not provide specific remedies for traditional knowledge-holders who feel that their knowledge has been misappropriated or otherwise misused. ${ }^{60}$ The next section considers the role of human rights in addressing the shortcomings of international environmental law in the protection of traditional knowledge.

\subsection{Traditional knowledge in human rights law}

Human rights law does not deal with traditional knowledge as a self-standing issue. Instead, the protection of traditional knowledge is part of the broader protection afforded to culture, which is at the heart of several human rights, ${ }^{61}$ including freedom of thought, conscience and religion; ${ }^{62}$ freedom of expression; ${ }^{63}$ and the prohibition of discrimination. ${ }^{64}$ The human right to culture is specifically enshrined in both foundational Covenants in the International Bill of Human Rights. ${ }^{65}$

57. As reported for example in: IPBES Task Force on Indigenous and Local Knowledge Systems (ILK), Sub-group for the Pollination Assessment, 'Indigenous and Local Knowledge about Pollination and Pollinators Associated with Food Production' (UNESCO 2015) <http://www.unesco. org/new/fileadmin/MULTIMEDIA/HQ/SC/pdf/IPBES_Pollination-Pollinators_Workshop.pdf> accessed 26 July 2017, 97.

58. Even though it is subject to compatibility with the protection of other human rights. Human Rights Council, Report by the Independent Expert in the Field of Cultural Rights, A/HRC/17/38 (2011), 64 and 74.

59. As observed also in Savaresi, 'The International Human Rights Law Implications of the Nagoya Protocol' (n 49), 78.

60. Ibid.

61. In this sense, see also ACHPR, Centre for Minority Rights Development (Kenya) and Minority Rights Group International on behalf of Endorois Welfare Council v Kenya, Communication No. 276/2003, 241.

62. International Covenant on Civil and Political Rights (New York, 16 December 1966, in force 23 March 1976), 999 UNTS 171 ['ICCPR'], article 18.

63. ICCPR, article 19.

64. ICCPR, article 26.

65. ICCPR, article 27; and International Covenant on Economic, Social and Cultural Rights (New York, 16 December 1966, 3 January 1976) 993 UNTS 3 ['ICESCR'], article 15. 
The rationale for protecting traditional knowledge under human right law is radically different from that observed in international environmental instruments. In human rights law the protection of traditional knowledge is an end in and of itself, ${ }^{66}$ and is not limited to instances when that protection is relevant for and compatible with the achievement of environmental objectives. The scope of protection is also different. International human rights law potentially covers all four levels identified in Figure 1.

Human rights law is therefore in principle relevant both for the promotion of the use of traditional knowledge and its protection at the national, subnational and local levels. Nevertheless, there are limitations to the role international human rights law can play, as only states that have ratified human rights treaties that protect the right to culture may be said to have specific obligations in this connection. ${ }^{67}$

The right to culture encompasses both free PIC and benefit-sharing requirements. In this regard, the Independent Expert in the Field of Cultural Rights has underscored how communities and individuals should be consulted and invited to actively participate in the identification, selection, classification, interpretation, preservation and safeguarding, stewardship, and development of cultural heritage. ${ }^{68}$ These activities require seeking the free PIC of all affected communities and relevant individuals. Researchers should specifically seek the free PIC of the communities and peoples whose cultural heritage they desire to investigate at all stages of research and dissemination. ${ }^{69}$

The right to culture furthermore encompasses the right to benefit from cultural heritage. $^{70}$ The latter right broadly resonates with the benefit-sharing requirements analysed above, but also potentially clashes with restrictions associated with the propertization and contractualization of access. Indeed, human rights bodies have specifically cautioned against the adverse consequences of globalization and the undue privatization of goods and services ${ }^{71}$ and highlighted the risks associated with propertization regimes. ${ }^{72}$

The wide-ranging obligations associated with the right to culture are especially pervasive in relation to indigenous peoples, in light of their right to self-determination. ${ }^{73}$ Human rights bodies have emphasized indigenous peoples' right to maintain, control, protect and develop their cultural heritage, traditional knowledge and cultural expressions. ${ }^{74}$ The United Nations Declaration on the Rights of Indigenous Peoples (UNDRIP) specifically refers to indigenous peoples' right to maintain, control, protect and develop 'manifestations of their sciences, technologies and cultures, including human and genetic resources, seeds, medicines, knowledge of the properties of

66. Even though it is subject to compatibility with the protection of other human rights. Human Rights Council, Report by the Independent Expert in the Field of Cultural Rights, A/HRC/17/38 (2011), 64 and 74.

67. The ICCPR has 168 parties; and the ICESR has 164 parties, whereas only 22 states have ratified International Labour Organization Convention 169 Concerning Indigenous and Tribal Peoples in Independent Countries (1989).

68. See Independent Expert in the Field of Cultural Rights (n 58), 80.

69. Ibid, 80(h).

70. Ibid, 79.

71. UN Committee on Economic, Social and Cultural Rights, General Comment No. 21, E/C.12/GC/21 (2009), 50.

72. Ibid.

73. ICCPR article 1, and Mahuika v New Zealand, Communication No. 547/1993 (2000).

74. ICESCR, article 15, paragraph 1(a); and General Comment No. 21, 37. 
fauna and flora, oral traditions, literatures, designs, sports and traditional games and visual and performing arts'. ${ }^{75}$

Human rights instruments leave little doubt that free PIC is required both for access to and the management of traditional knowledge. ${ }^{76}$ A mutually supportive interpretation of international human rights and international environmental law obligations would therefore suggest that free PIC is a requirement both for the use of traditional knowledge and in the design and implementation of measures contained within the environmental instruments analysed in this article. On benefit-sharing, a mutually supportive interpretation of human rights and environmental law would furthermore entail states' positive obligations to oversee contractual arrangements related to the access and use of traditional knowledge and to address power imbalances amongst parties, for example through capacity building and other support schemes. ${ }^{77}$

Finally, a combined reading of states' obligations associated with the right to culture and the right to access to justice suggests that effective remedies, including judicial ones, should be made available to individuals and communities who feel that their traditional knowledge is not fully protected. ${ }^{78}$ In at least one instance, the Committee on Economic, Social and Cultural Rights has sanctioned a lack of adequate protection of the right to culture, making specific reference to traditional knowledge. ${ }^{79}$ The right to culture therefore has the potential to complement the protection of traditional knowledge in international law by providing an entry point for complaints about the misuse and misappropriation of traditional knowledge and the reporting of unauthorized access, thus facilitating access to remedies. ${ }^{80}$ Even though international human rights law has not developed specific tools to prevent the misuse and misappropriation of traditional knowledge, it nonetheless potentially provides international remedies that may be used by traditional knowledge-holders who feel their knowledge has been misappropriated or otherwise misused. It is nevertheless also important to acknowledge that these remedies are no guarantee of protection and are therefore limited in their capacity to redress human rights abuses and ultimately to address their root causes.

In sum, international human rights law potentially complements the protection of traditional knowledge in international environmental instruments in three ways. First, it provides procedural obligations addressing the inclusion of traditional knowledgeholders in inventorying processes, including their empowerment to carry out documentation if they so wish. Second, it requires the outcomes of such documentation processes to align with the substantive rights of traditional knowledge-holders. This includes, for example, the right to be recognized as contributors in science creation and assessment processes. Third, human rights law may provide access to remedies at the domestic and, potentially, the international level to complain about breaches of knowledgeholders' rights. Even though international human rights law has so far been only sporadically used for the protection of traditional knowledge, the potential to apply it across the

75. UNDRIP, article 31.

76. ICESCR, article 15, paragraph 1(c); and Independent Expert in the Field of Cultural Rights (n 58), 80.

77. As argued also in Savaresi, 'The International Human Rights Law Implications of the Nagoya Protocol' (n 49), 54.

78. Independent Expert in the Field of Cultural Rights (n 58), 64 and 80(1).

79. Concluding Observations of the Committee on Economic, Social and Cultural Rights: Russian Federation, E/C.12/RUS/CO/5 (2011), 34.

80. As argued also in Savaresi, 'The International Human Rights Law Implications of the Nagoya Protocol' (n 49). 
board appears underexplored and deserving of further exploration. Some reflections on how this potential may be realized in the climate regime are provided in the next section.

\section{TRADITIONAL KNOWLEDGE AND INTERNATIONAL CLIMATE CHANGE LAW}

International climate change law-making on traditional knowledge has only very recently entered a formal regulatory phase, with the adoption of the Paris Agreement. ${ }^{81}$ This section considers the de lege lata developments in relation to traditional knowledge that have occurred under the climate regime thus far, as well as de lege ferenda developments that may occur in future.

\subsection{Developments de lege lata}

The role of traditional knowledge in climate change science and policy-making was first recognized by the inter-governmental scientific body entrusted to assist states in assessing the magnitude, timing and potential impacts of climate change, as well as possible response strategies - the Intergovernmental Panel on Climate Change (IPCC). ${ }^{82}$

Firstly, the IPCC recognized that scientists increasingly rely on traditional knowledgeholders' observations for the assessment of climate change, especially in vulnerable environments. ${ }^{83}$ Here, the IPCC refers to the use of traditional empirical knowledge, on matters like plants, soils and landscape, as a source of data contributing to the process of observation and assessment of climate change. ${ }^{84}$ In this connection, it is not traditional knowledge ex se that is at issue, but rather observations concerning environmental changes made by traditional knowledge-holders, on the basis of traditional knowledge. Such knowledge is unlikely to be used or developed for commercial purposes. Yet the interaction between traditional knowledge-holders and scientists raises questions about how the contributions made by the latter to the assessment process is acknowledged. To date, the IPCC has recommended knowledge partnerships between traditional knowledge-holders and scientists ${ }^{85}$ but has not created pathways to make this happen. ${ }^{86}$ Following the adoption of the Paris Agreement, however, one

81. Decision 1/CP.21, 136.

82. UN General Assembly, Protection of Global Climate for Present and Future Generations of Mankind, A/RES/43/53 (1988), 5.

83. IPCC, Climate Change 2007: Impacts, Adaptation and Vulnerability. Contribution of Working Group II to the Fourth Assessment Report of the Intergovernmental Panel on Climate Change Contribution (Cambridge University Press, Cambridge 2007), 138 and 673.

84. IPCC (n 8), 765.

85. See: UNFCCC Secretariat, Best practices and available tools for the use of indigenous and traditional knowledge and practices for adaptation, and the application of gender-sensitive approaches and tools for understanding and assessing impacts, vulnerability and adaptation to climate change, FCCC/TP/2013/11 (2013), 8.

86. The IPCC has only co-convened an international expert meeting on 'Indigenous Peoples, Marginalized Populations and Climate Change: Vulnerability, Adaptation and Traditional Knowledge' on 19-21 July 2011 in Mexico City, and sponsored a meeting on 'Climate Change Mitigation with Local Communities and Indigenous Peoples: Practices, Lessons Learned and Prospects' on 26-28 March 2012, in Cairns, Australia. 
of the subsidiary bodies of the climate regime has noted the IPCC's role in strengthening the global response to climate change, including by considering indigenous peoples' and traditional knowledge. ${ }^{87}$ Whether and how this timid reference will open the way to IPCC work on traditional knowledge analogous to that carried out in the context of the IPBES, ${ }^{88}$ however, remains to be seen.

Secondly, the IPCC has recognized the role of traditional knowledge in designing climate change response measures. ${ }^{89}$ In this connection, both empirical and resource management knowledge on matters such as water and soils are potentially quite relevant. Traditional knowledge on some of these issues already falls within the scope of the international environmental law instruments analysed above. Therefore, the question arises whether and how these instruments already cover regulatory needs in relation to climate change response measures.

So far, the climate regime's subsidiary bodies have undertaken some action to collate information concerning existing traditional knowledge databases. ${ }^{90}$ Parties to the climate regime, however, have not adopted specific guidance concerning this compilation of information. Experts ${ }^{91}$ have recommended the drafting of specific guidelines to mobilize traditional knowledge and link it with scientific knowledge in decisionmaking processes, in line with relevant international policies and best practices and through processes that include knowledge-holders. ${ }^{92}$ To date, this invitation has not been followed up. ${ }^{93}$ However, this matter may be looked at afresh in the context of the ongoing debate on the operationalization of the local communities and a platform for indigenous peoples established with the adoption of the Paris Agreement.

In the first half of 2017, parties and observer organizations were invited to submit their views on the purpose, content and structure of this new platform. ${ }^{94}$ These views were discussed at an open multi-stakeholder dialogue organized in conjunction with an intersessional meeting of the climate regime's subsidiary bodies in Bonn. ${ }^{95}$ The discussions identified three possible functions for the platform.

First, it was suggested that the platform may facilitate the exchange of experiences and the sharing of best practices for working with local and indigenous knowledge, including the use of safeguards and the exchange of information with other processes outside the climate regime. Second, it was suggested that the platform may build

87. SBSTA, Research and Systematic Observation, FCCC/SBSTA/2017/L.3 (2017), 6.

88. For an early analysis of the IPBES's work on this, see C Chiarolla and A Savaresi, 'Indigenous Challenges Under IPBES: Embracing Indigenous Knowledge and Beyond', in M Hrabanski and D Pesche (eds), The Intergovernmental Platform on Biodiversity and Ecosystem Services (IPBES): Challenges, Knowledge and Actors (Routledge, Abingdon 2016).

89. IPCC (n 8), 758 and 766.

90. Revised Workplan of the Adaptation Committee for 2016-2018, as annexed to document FCCC/SB/2015/2 (2016).

91. UNFCCC Secretariat, Best practices and available tools for the use of indigenous and traditional knowledge and practices for adaptation, and the application of gender-sensitive approaches and tools for understanding and assessing impacts, vulnerability and adaptation to climate change, FCCC/TP/2013/11 (2013), 10 and 20, respectively.

92. Ibid, 25.

93. Decision 4/CP.20, Report of the Adaptation Committee, FCCC/CP/2014/10/Add.2 (2015), 4.

94. Report of the Conference of the parties on its twenty-second session, held in Marrakech from 7 to 18 November 2016, Part I, FCCC/CP/2016/10 (2016), 163-7.

95. The meeting's agenda and background information may be found at: <http://unfccc.int/ meetings/unfccc_calendar/items/10151.php> accessed 27 July 2017. 
capacity in indigenous peoples and local communities to effectively engage in international climate change governance, thereby increasing the inclusivity and transparency of decision-making on matters such as adaptation and loss and damage. Third, it was suggested that the platform may facilitate the integration of diverse knowledge systems, practice, innovation and the engagement of indigenous peoples and local communities in climate-change-related actions, programmes and policies, including by: supporting national and regional efforts to build synergies between local and indigenous knowledge and science to inform climate change decisionmaking; and facilitating cooperation to support local communities and indigenous peoples to apply their traditional knowledge and practice to climate action. The multi-stakeholder dialogue saw a lively debate on these issues, with the participation of representatives from states, international organizations and civil society. ${ }^{96}$ These matters will be further discussed at the meeting of the parties to the climate regime to be held in November 2017. It nevertheless already seems clear that the platform may engage in capacity-building and inventorying processes, and may include the elaboration of safeguards for the latter, as well as for greater involvement of traditional knowledge-holders in the elaboration and implementation of climate change response measures.

While decisions on the shape and functions of the platform remain to be determined, the matter of traditional knowledge-holders' involvement in the elaboration and implementation of climate change response measures has already been addressed in the context of measures to maintain and enhance forest carbon storage in developing countries, commonly referred to by the acronym 'REDD+'. ${ }^{97}$ REDD+ safeguards expressly ask parties to respect 'the knowledge and rights of indigenous peoples and members of local communities, by taking into account relevant international obligations, national circumstances and laws, and noting that the United Nations General Assembly has adopted the United Nations Declaration on the Rights of Indigenous Peoples'. ${ }^{98}$ This explicit link between REDD+ safeguards and existing bodies of laws concerning traditional knowledge has two main implications.

First, as virtually all developing countries parties eligible to participate in REDD+ have ratified some human rights treaties, ${ }^{99}$ a mutually supportive interpretation of their obligations suggests that free PIC is required for all REDD+ activities. ${ }^{100}$ This interpretative guidance has already been followed by the UN-REDD Programme,

96. A reportage of the meeting is available at: <http://enb.iisd.org/climate/sb46/enbots/ 16may.html\#event> accessed 27 July 2017.

97. The scope of REDD+ includes both activities aimed at reducing forest emissions (such as reduced deforestation and forest degradation and sustainable forest management), as well as activities aimed at increasing forest carbon sequestration (such as afforestation and reforestation). See Decision 1/CP.16, 70 and article 5.2 Paris Agreement.

98. Decision 1/CP.16, The Cancún Agreements: Outcome of the Work of the Ad Hoc Working Group on Long-term Cooperative Action under the Convention (2010), FCCC/CP/2010/7/ Add.1, Appendix 1, 2(c).

99. Virtually all developing country parties to the UNFCCC eligible to participate in REDD+ have ratified the International Covenant on Civil and Political Rights, and the International Covenant on Economic, Social and Cultural Rights. Several have also ratified regional human rights treaties.

100. As argued also in A Savaresi, 'The Legal Status and Role of Safeguards', in C Voigt (ed), Research Handbook on REDD+ and International Law (Edward Elgar Publishing, Cheltenham, UK and Northampton, MA, USA 2016), 145. 
which has specifically adopted a human-rights-based approach to REDD+, ${ }^{101}$ including requirements on free PIC embedded in international and regional human rights law. ${ }^{102}$

Second, traditional knowledge relevant for REDD+ activities may also fall within the scope of the Convention on Biological Diversity (CBD) - for example, in relation to empirical knowledge on forests and their management, which may be used for the verification of carbon stocks and the design of REDD+ policies. CBD obligations thus complement those under the climate regime, providing guidance that is both relevant and has been adopted under a treaty ratified by virtually all states in the world. ${ }^{103}$ Indeed, CBD parties have already emphasized the potential for CBD guidance to assist parties to the climate regime in the implementation of REDD+ activities. ${ }^{104}$ Whether and how this guidance will be taken into account in practice remains to be seen. It nevertheless seems clear that, at least in connection with REDD+, the treatment of traditional knowledge under the climate regime is already linked to other international law instruments. REDD+ safeguards may thus be regarded a precedent for the cross-fertilization between international climate change, human rights and other environmental law instruments. ${ }^{105}$ Such cross-fertilization may be further replicated across the climate regime, as the next section explains.

\subsection{Developments de lege ferenda}

Even though various forms of traditional knowledge falling within the first two levels identified in Berkes's conceptualization are at play in the climate regime, the only concrete regulatory developments thus far are geared towards the promotion of the use of traditional knowledge, both as a means to assess climate change impacts and to design and implement climate change response measures, especially in the context of adaptation and REDD+. Contrary to developments in other international environmental instruments, the matter of the protection of traditional knowledge from commercial exploitation has not surfaced in the climate regime.

These developments raise the question of whether the climate regime poses regulatory challenges that are different from those experienced under the international instruments reviewed in Section 3. If it does, the question then is how these challenges might be addressed; if it doesn't, then the question is to what extent existing international law instruments already address the regulatory questions emerging under the climate regime. In this connection, the Bonn multi-stakeholder dialogue specifically

101. UN-REDD, Social and Environmental Principles and Criteria (2012), 2-3.

102. UN-REDD, Guidelines on Free, Prior and Informed Consent (2013).

103. A Savaresi, 'The Role of REDD in Harmonising Overlapping International Obligations', in E Hollo, K Kulovesi and M Mehling (eds), Climate Change and the Law: A Global Perspective (Springer, Dordrecht et al. 2013), 150.

104. Decision XI/19, Biodiversity and Climate Change Related Issues, UNEP/CBD/COP/ DEC/XI/19 (2012), Annex, 13. For a detailed review, see A Savaresi, 'Reducing Emissions from Deforestation in Developing Countries under the United Nations Framework Convention on Climate Change. A New Opportunity for Promoting Forest Conservation?' in F Maes et al. (eds), Biodiversity and Climate Change: Linkages at International, National and Local Levels (Edward Elgar Publishing, Cheltenham, UK and Northampton, MA, USA 2013).

105. As argued also in Savaresi, 'The Role of REDD in Harmonising Overlapping International Obligations' (n 103). 
noted the need to take heed of guidance on traditional knowledge adopted under other international processes, as well as opportunities to build synergies between these processes. ${ }^{106}$

This article has shown that state obligations concerning the treatment of traditional knowledge depend on both the traditional knowledge at stake and on the other treaties that parties to the climate regime have ratified. With regard to the protection of traditional knowledge, there seems to be little need for international climate change law to duplicate regulatory efforts undertaken under other environmental instruments and/or international human rights law. It would instead make sense to build linkages between obligations under applicable instruments (for states that are parties to these treaties) and to raise parties' awareness of linkages, as has happened in the context of REDD+.

The situation is very different in relation to the promotion of the use of traditional knowledge, both in the assessment and the design and implementation of climate change measures. Unlike some international environmental law instruments reviewed above, international climate treaties do not include obligations relating to the documentation of traditional knowledge. However, measures in this connection may well be adopted in future, in the context of ongoing negotiations on the indigenous peoples and local communities' platform. Should this occur, parties to the climate regime will be faced with regulatory questions similar to those that have confronted parties to the UNCCD and the UNESCO Convention. The practice under these instruments is therefore an important frame of reference for understanding how international obligations on traditional knowledge documentation could be crafted and their perceived shortcomings. The scope of these existing instruments is furthermore likely to overlap, at least in part, with that of the climate regime, depending on the nature of the traditional knowledge at stake. For example, empirical and resource management knowledge on desertification falling within the scope of the UNCCD is likely to be relevant under the climate regime also. It is therefore important to understand how and to what extent the legal obligations enshrined in the UNCCD may already address questions about the documentation of traditional knowledge that might arise in the climate regime, and what outstanding regulatory needs exist.

In this regard, there seems to be a convergence in international law instruments on the need to empower traditional knowledge-holders in the creation and assessment of scientific processes. The practice of the IPBES has evidenced the need for adequate finance and capacity-building for greater and better interaction between traditional knowledge-holders and scientists. Furthermore, international human rights obligations already require states to enable traditional knowledge-holders' involvement in the creation and assessment of scientific processes. Developments initiated with the adoption of the Paris Agreement may therefore pave the way for greater international cooperation, as well as for the elucidation of states' obligations in this regard.

Similarly, interpretation of states' obligations on the use of traditional knowledge in the design and implementation of climate change response measures could take heed of the abundant practice on public participation, access to information and access to justice. ${ }^{107}$ The question is to determine the extent to which these obligations apply in relation to traditional knowledge. In this regard, while some traditional knowledge

106. Notes on file with the author.

107. This practice is comprehensively reviewed in: Report of the Independent Expert on the issue of human rights obligations relating to the enjoyment of a safe, clean, healthy and sustainable environment, John H Knox, Mapping Report, A/HRC/25/53, 30 December 2013. 
falling within the scope of the CBD and the ITPGR may fall also within the remit of the climate regime, there is a vast body of traditional knowledge which does not. It is with regard to the latter that international human rights obligations are of particular relevance.

As noted above, the Paris Agreement has rendered the climate regime the only body of international environmental law to include a specific reference to parties' existing human rights obligations. ${ }^{108}$ While such a reference does not impose new human rights obligations on states, it draws attention to the need to comply with existing ones. ${ }^{109}$ Even though the parties to the Paris Agreement are yet to draw up a dedicated legal framework on traditional knowledge, and may never do so, the Agreement provides an entry point for considering states' existing obligations under international human rights law. Developments in the context of REDD+ and climate finance seemingly indicate that parties to the climate regime already share this understanding. ${ }^{110}$ With the implementation of the Paris Agreement, a similar approach to managing the interplay between international law obligations may be explored in relation to other climate change response measures.

\section{CONCLUSION}

This article has reflected on the incipient debate on traditional knowledge in the climate regime, in light of extant international law obligations and practice. It has explained that numerous international law instruments already contain obligations supporting the protection of traditional knowledge at the national, subnational and local levels. International biodiversity law is a crucial frame of reference in this regard, and has made considerable strides in identifying best practices and voluntary guidance, which in some cases have solidified into hard law obligations. International law has also made some effort to avoid the creation of perverse incentives concerning the misuse and misappropriation of traditional knowledge. However, regulatory developments have been patchy and context-specific. Finally, international law provides limited remedies to traditional knowledge-holders who believe that their knowledge has been misappropriated or otherwise misused. Human rights law may lend itself to this purpose, but its potential largely remains to be tested in practice.

The evolution of international law on traditional knowledge is characterized by a tension between ensuring the contribution of traditional knowledge to the provision of global public goods and the need to protect the rights of its holders. This article has shown that benefit-sharing and free PIC requirements are the common thread running through existing international law instruments dealing with traditional knowledge. However, free PIC and benefit-sharing requirements in international environmental law are context-specific, and depend on the kind of traditional knowledge at stake and on the traditional knowledge-holders involved.

108. Paris Agreement, Preamble and Decision 1/CP.16, 8, according to which: 'parties should, in all climate change related actions, fully respect human rights'.

109. As argued also in A Savaresi , 'Climate Change and Human Rights: Fragmentation, Interplay and Institutional Linkages', in S Duyck, S Jodoin and A Johl (eds), Routledge Handbook of Human Rights and Climate Governance (Routledge, Abingdon 2018) <https://papers.ssrn. com/abstract=2902662 > accessed 31 March 2017, 9.

110. For developments in climate finance standards, see ibid, 10-11. 
As is often the case with international law, the regulatory picture emerging from the interplay between various instruments is composite. There is evident potential for interpreting extant international law on traditional knowledge in ways that are mutually supportive and for promoting synergies between international human rights and environmental law obligations.

As they work out the details for the operationalization of the indigenous peoples and local communities' platform, parties to the climate regime should consider adopting guidelines on the use of traditional knowledge in scientific assessment and documentation processes. Existing international law can assist parties as they attend to this complex task, but a blanket import of guidance adopted under other instruments into the climate regime is unlikely, because of considerations related to treaty membership, as well as a lack of political will to set a precedent in this regard. ${ }^{111}$

In terms of international law-making, parties to the climate regime are therefore at a crossroads. They may decide to stick with the status quo and avoid elaborating specific guidance on traditional knowledge. Alternatively, and similarly to what happened with REDD+, they may make reference to guidance and obligations under other international processes. Finally, parties may decide to embrace the challenge and engage in drafting guidance or even obligations on the use of traditional knowledge for purposes associated with the climate regime. The role of the climate change law on these issues is largely residual, and should build on existing international law whenever relevant, without duplicating efforts made under other instruments. If and when parties to the climate regime decide to attend to this complex task, the instruments reviewed in this paper will doubtlessly provide an expedient point of departure to explore this new frontier of international law.

While the need to increase synergies and avoid duplication of efforts between international processes on this issue are real and clear, it is also important to remember that international law is still far from having achieved the objectives of adequately protecting traditional knowledge and respectfully promoting its use. Much work remains to be done to clarify and implement states' obligations in this connection. The unfolding debate in the context of the climate regime provides a valuable opportunity to look at past regulatory developments, to take heed from lessons learnt, and hopefully to surmount the obstacles encountered thus far.

111. Savaresi, 'Climate Change and Human Rights: Fragmentation, Interplay and Institutional Linkages' (n 109), 15. 